\title{
Argon plasma coagulation performed as a treatment for restenosis after placement of two duodenal self-expandable metallic stents
}

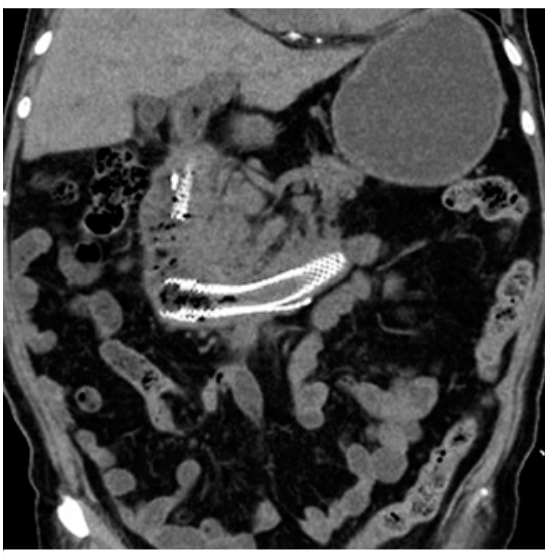

- Fig. 1 Computed tomographic finding in an 82-year-old man with recurrent gastric outlet obstruction after placement of two SEMS. The first stent (WallFlex duodenal stent, $22 \mathrm{~mm} \times 6 \mathrm{~cm}$, uncovered type) was inserted into the third portion of the duodenum. The second duodenal stent (WallFlex duodenal stent, $22 \mathrm{~mm} \times 9 \mathrm{~cm}$, covered type) was inserted as a stent-in-astent for obstruction of the first SEMS due to tumor ingrowth.

Malignant gastroduodenal outlet obstruction (MGOO) is occasionally seen in patients with advanced pancreatic cancer. The endoscopic placement of selfexpandable metallic stents (SEMS) has proven to be an effective treatment for MGOO [1,2]. However, the optimal treatment for MGOO that recurs after the placement of a duodenal SEMS remains unknown. Although a few reports have shown argon plasma coagulation (APC) to be effective for treating stenosis of metallic esophagogastric stents [35], the application of APC to malfunction of a duodenal SEMS has not yet been reported. Hence, we are the first to report the case of a patient who underwent APC for recurrent MGOO after placement of two duodenal SEMS.

An 82-year-old man with unresectable locally advanced pancreatic cancer underwent gemcitabine monotherapy after insertion of a duodenal SEMS for MGOO

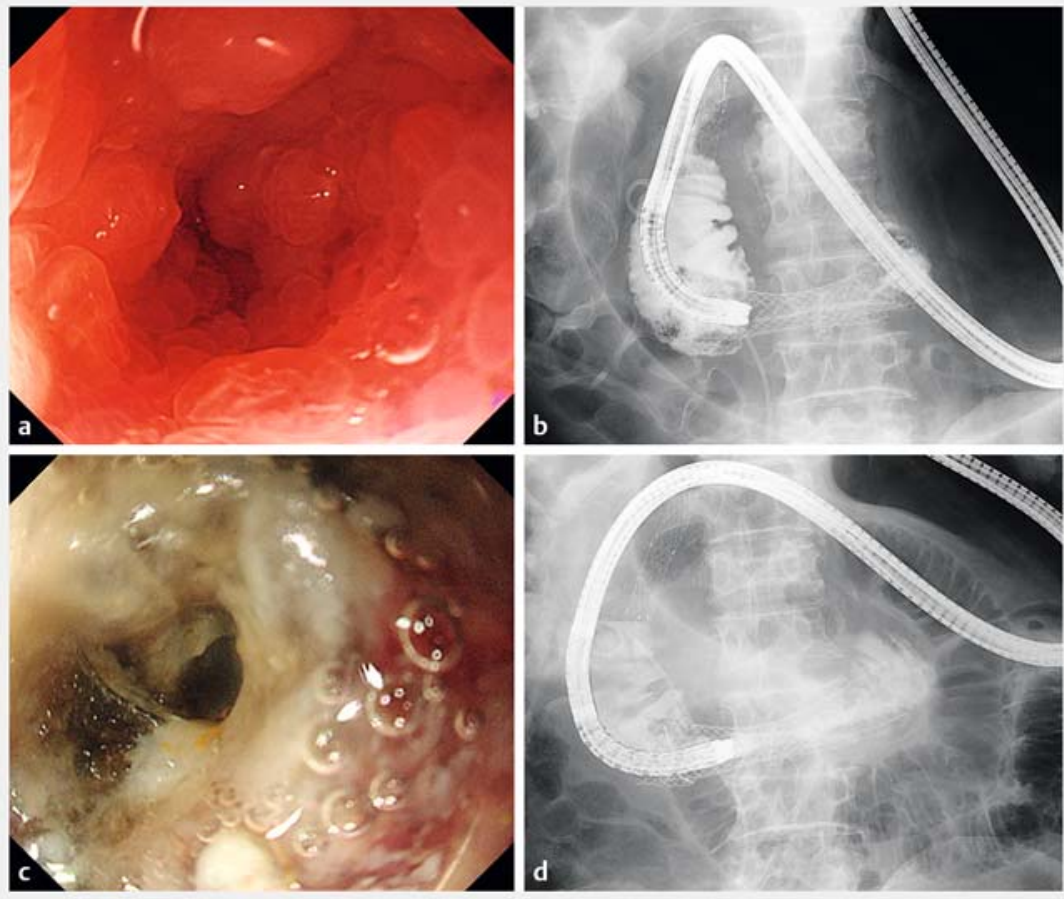

- Fig. 2 a, b Before the argon plasma coagulation treatment, imaging confirmed recurrent obstruction of the duodenal SEMS: a endoscopic findings, b fluoroscopic findings. c, d After the procedure, the duodenal lumen was visible: $\mathbf{c}$ endoscopic view, $\mathbf{d}$ fluoroscopic view.
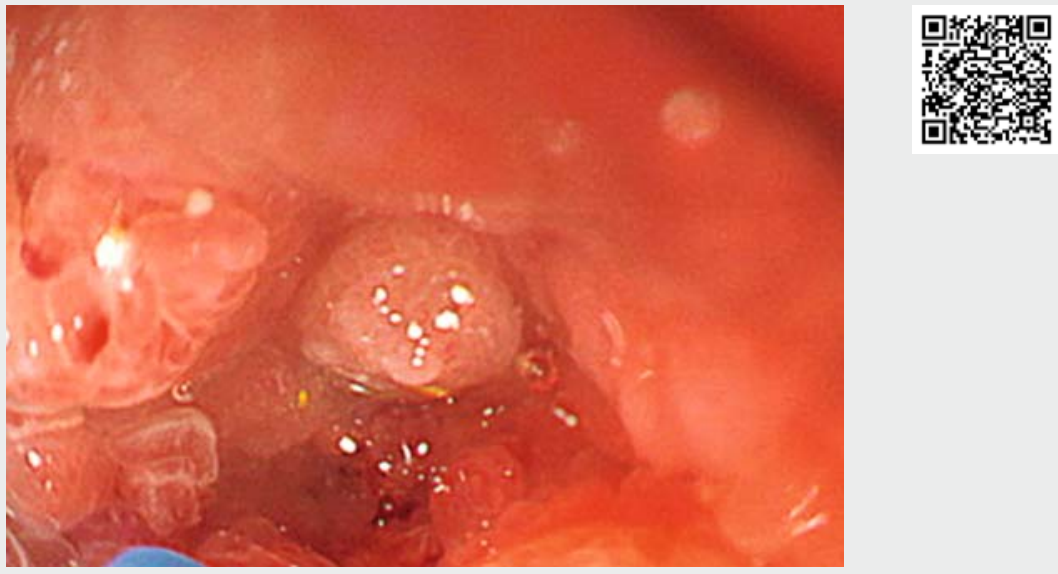

Video 1 Argon plasma coagulation performed as a treatment for restenosis after placement of two duodenal self-expandable metallic stents. 
and endoscopic ultrasound-guided choledochoduodenostomy for obstructive jaundice. A year later, when MGOO recurred, an additional duodenal SEMS was inserted to treat it. Approximately 2 months after the second SEMS placement, the patient was admitted to our hospital with vomiting. Computed tomography revealed the SEMS to be obstructed by tumor ingrowth ( $\mathbf{F i g . 1}$ ). Insertion of a third SEMS seemed contraindicated on the grounds of cost and the patient's overall poor prognosis. We therefore attempted to treat the duodenal SEMS malfunction using a $2.3-\mathrm{mm}$ axial APC probe at the following settings: gas flow rate $1 \mathrm{~L} / \mathrm{min}$, current $40-50 \mathrm{~W}$, effect 2 ( $\downarrow$ Video 1 ). Although we were able under endoscopic guidance to cauterize the hyperplastic mucosa in the proximal part of the SEMS, the vomiting showed no improvement. The APC treatment was repeated 4 days later. In addition, under fluoroscopic guidance cauterization was performed along the guidewire in the distal part of the SEMS without any complications ( Fig. 2). GOO-induced symptoms were not observed for 4 months after the APC treatment. After that, the patient died from pancreatic cancer progression.

APC may be an effective treatment for recurrent duodenal obstruction after SEMS placement.

Endoscopy_UCTN_Code_CPL_1AH_2A J

\section{Competing interests}

The authors declare that they have no conflict of interest.

\section{The authors}

Akihisa Ohno ${ }^{1,2}$, Toyoma Kaku1, ${ }^{1,2}$, Masayuki Hijioka $^{1,2}$, Naohiko Harada ${ }^{1,2}$, Makoto Nakamuta $^{1,2}$, Ken Kawabe ${ }^{1,2}$

1 Department of Gastroenterology, National Hospital Organization Kyushu Medical Center, Fukuoka, Japan

2 Clinical Research Institute, National Hospital Organization Kyushu Medical Center, Fukuoka, Japan

\section{Corresponding author}

\section{Ken Kawabe, MD, PhD}

Department of Gastroenterology, National Hospital Organization Kyushu Medical Center, 1-8-1 Jigyohama, Chuo-ku, Fukuoka 810-8563, Japan

Fax: +81-92-847-8802

kkawabe19@gmail.com

\section{References}

[1] Sasaki R, Sakai Y, Tsuyuguchi T et al. Endoscopic management of unresectable malignant gastroduodenal obstruction with a nitinol uncovered metal stent: a prospective Japanese multicenter study. World J Gastroenterol 2016; 22: 3837-3844

[2] Tringali A, Didden P, Repici A et al. Endoscopic treatment of malignant gastric and duodenal strictures: a prospective, multicenter study. Gastrointest Endosc 201479: 66-75
[3] Sigounas DE, Krystallis C, Couper G et al. Argon plasma coagulation compared with stent placement in the palliative treatment of inoperable oesophageal cancer. United European Gastroenterol J 2017; 5: 21-31

[4] Dumoulin FL, Plassmann D. Tissue hyperplasia following placement of a biodegradable stent for a refractory esophageal stricture: treatment with argon plasma coagulation. Endoscopy 2012; 44: 356-357

[5] Kishimoto T, Imamura H, Kawabata R et al. A case with anastomotic stricture after total gastrectomy that was successfully treated with argon plasma coagulation. Gan To Kagaku Ryoho 2010; 37: 2473-2474

\section{Bibliography}

\section{Endoscopy 2021; 53: E240-E241}

Dol 10.1055/a-1248-1991

ISSN 0013-726X

published online 23.9.2020

(C) 2020. Thieme. All rights reserved.

Georg Thieme Verlag KG, Rüdigerstraße 14,

70469 Stuttgart, Germany

\section{ENDOSCOPY E-VIDEOS}

https://eref.thieme.de/e-videos

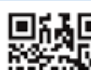

Endoscopy E-Videos is a free access online section, reporting on interesting cases and new

techniques in gastroenterological endoscopy. All papers include a high quality video and all contributions are freely accessible online.

This section has its own submission website at https://mc.manuscriptcentral.com/e-videos 